International Journal of Agriculture, Environment and Bioresearch

Vol. 5, No. 06; 2020

ISSN: 2456-8643

\title{
POWDER MIXTO MANUFACTURE PELLETS AND INCREASE THE SURVIVAL LEVEL OF ENTOMOPATHOGENIC NEMATODES (Steinernema glaseri) CONTAINED WITHIN
}

\author{
L.V. Bustamante-Espinosa ${ }^{1,2}$, A. Castañeda-Ovando ${ }^{3}$, J. Hernández-Ávila ${ }^{3}$, M. Reyes-López3, P. Montes- \\ García $^{4}$ and V.G.Jiménez-Quero ${ }^{4}$ \\ ${ }^{1} \mathrm{MScStudent}$ of Maestría en Ciencias en Conservación y Aprovechamiento de Recursos Naturales, Instituto \\ PolitécnicoNacional, CIIDIR Oaxaca, México \\ ${ }^{2}$ Universidad Politécnica de Francisco I. Madero, Hidalgo, México \\ ${ }^{3}$ Universidad Autónoma del Estado de Hidalgo, México \\ ${ }^{4}$ Instituto Politécnico Nacional. CIIDIR Oaxaca, México
}

https://doi.org/10.35410/IJAEB.2020.5570

\begin{abstract}
The encapsulation of Entomopathogenic Nematodes (EPNs) in pellets is a promising alternative to use as a biological control method. However, it is necessary that the nematodes survive as long as possible inside the pellet before its release in field. In this research were to evaluate (at two periods of time)the survival rates(SRs) of EPNs contained inside of pellets. The pellets were made with the combination of three materials powders: bentonite clay(B), diatomaceous earth (D) and sugarcane bagasse ash (SCBA). In order to adequately manufacture the pellets (quasispherical shaped) and avoid their early disintegration, the decision was made to combine $95 \% \mathrm{~B}+5 \% \mathrm{D}$ and consider this combination as a control mixture $(\mathrm{C})$. Three ternary mixtures were prepared, a mixture with $90 \% \mathrm{~B}+5 \% \mathrm{D}+5 \% \mathrm{SCBA}$ (T5), a mixture with $85 \% \mathrm{~B}+5 \% \mathrm{D}+10 \% \mathrm{SCBA}(\mathrm{T} 10)$ and a mixture with $90 \% \mathrm{~B}+5 \% \mathrm{D}+5 \% \mathrm{SCBA}(\mathrm{T} 15)$. Eight pellets of each mixture were made (not including nematodes in their interior) and its capillary absorption was evaluated at 21 and 30 days after its elaboration. Subsequently, ten pellets per mixture with nematodes inside were elaborated and stored at room temperature. The evaluation of the survival level of the nematodes was carried out after 21 and 30 days of storage, respectively. The results show that at 21 days the pellets made with the four mixtures followed the same trend in their absorption capacity. From 0 to 240 seconds was the period of time in which there was a higher percentage of absorption (about $70 \%$ of the total) and from 240 seconds, the percentage of absorption was lower. The pellets made with the T15 mixture had the longest time to saturate (2300 seconds). At 30 days the pellets made with mixture $\mathrm{C}$ had the highest absorption capacity and saturated in the minor time (1200 seconds). The pellets made with the T10 and T15 mixes had a similar absorption capacity, however, the pellets made with the T15 mix had the longest saturation time of 2400 seconds. With respect to survival rateat 21 days the following was obtained:the nematodes encapsulated inside the pellets manufactured with the T10 mixture had the highest survival rate (62\%) and the nematodes encapsulated inside the pellets made with the control mix (C) had the lowest survival rate (11\%). The SRs of the encapsulated nematodes in the pellets manufactured with the T5 and T15 mixtures was 33\% and 35\% respectively.At 30 days the SRs of the EPNs encapsulated in the pellets of all the mixtures were slightly lower than those obtained at 21 days. The addition of $10 \%$ SCBA to the mixture of
\end{abstract}


Vol. 5, No. 06; 2020

ISSN: 2456-8643

powdered materials for the manufacture of pellets, improved the absorption and water retention capacity in them, which was beneficial in increasing the survival rate of EPNs. Using amounts of SCBA greater than $10 \%$ causes greater water absorption, expansion and disintegration of the pellets; therefore, the death of more nematodes.

Keywords: Biological control method, encapsulation, materials, capillary absorption, water retention capacity.

\section{INTRODUCTION}

The encapsulation of Entomopathogenic Nematodes (EPNs) in pellets is a promising alternative to use as a biological control method. This method is effective and does not cause any harm to the human health, domestic animals or plants; neither pollute the environment and the plagues do not become resistant to these products.

A direct application could be for the control of the pest Phyllophaga spp. For the biological control of Phyllophagaspp, the use of natural enemies such as Entomopathogenic Nematode (EPN)is a good alternative. The EPN infect the bodies of the plague larvae located in the root of the corn plant through the mouth, spiracles and anus to finally cause their death.

After production, EPNs are not applied immediately in corn fields, they are generally stored for later transport and release; however, the low Survival Rate (SR) of Entomopathogenic Nematodes caused during storage is a limiting factor for the massive production of biological pesticides (Grewal, 2002). Therefore, it is required to encapsulate the EPNs within pellets made with materials that allow increasing their life time during the storage stage.

Among the first attempts to encapsulate EPNs, Kaya et al. (1987) used apolymeric matrix containing calcium alginate. This material is biodegradable, allowing the EPNs to emerge from the capsules. The EPNs lasted eight months in closed containers which were kept at $4{ }^{\circ} \mathrm{C}$ and lasted three to four months at room temperature. Nevertheless, for the implementation of this encapsulation method a previous application of sodium citrate is required to release the EPNs from the alginate gel matrix. This last application and the use of several sieves and containers extended the extraction time and invalidated its implementation.

Silver et al. (1995) patented an invention concerns new methods for producing pellets and formulating nematodes intosuch granules for prolonged storage and convenientapplication.The materials used in the formulation of the pellets were: silica, diatomaceous earth,hydroxyethyl cellulose, clay, pre-gelled clay,lignosulfonate, modified starch, pre-gelatinized starch,a super absorbent and a combination of one or morethereof.However, the patent does not provide theamounts or percentages of each of material used.

In another study, Mendoza (2012) investigated the effect of the mechanical operations of pelleting onsurvival time in entomopathogenic nematodes.Nematodes of the species Steinernema glaseri wereencapsulated in diatomaceous earth and attapulgite indifferent proportions. The counting ofthe surviving nematodes was conducted daily by the method of Chen and Glazer (2005). The results showthat the mechanical encapsulation process doubles thetime of survival of 
Vol. 5, No. 06; 2020

ISSN: $2456-8643$

the nematodes reported for those manually processed (Girón, 2008). The survival of nematodes in the first three days was $100 \%$, whichgradually decreases. The best results were obtained withpellets made from diatomaceous earth, Celite 209 andcactus mucilage, posting 22\% mortality at day eight.

Finally, Hiltpold et al. (2012) developed a solution with a high concentration of $\mathrm{Ca}^{+2}$ ions with the addition of alginate, resulting in theformation of a coat surrounding the liquid core; thecore was prepared by mixing deionized water withgluconolactone and then $H$. bacteriophora EPN wasadded. The encapsulated EPNs were moreefficient than those sprayed with water in the control ofthe corn rootworm Diabroticavirgifera. Thisformulation represents a significant progress for thedirect application in the field; however, the reducednumber of nematodes per granule was a drawback forits distribution and mass application.

The previous results allow us to infer that a suitable combination of materialswith which the pellets are manufactured is a determining factor in the survival percentage of the EPN contained within.Based on this finding, the objective of this research was to evaluate (at two periods of time) the survival rates (SRs) of EPNs contained inside of pellets made with the combination of three different powder.A series of pellets were manufactured consideringseveral combinations of bentonite clay, diatomaceous earth, and sugarcane bagasse ash by the rolling method.

\section{MATERIALS (powders)}

Bentonite clay (B) is used as an animal feed supplement, as a pelletizing aid in the production of animal feed pellets, as well as a flowability aid for unconsolidated feed ingredients such as soy meal (Stojiljković and Stojiljković, 2017). Bentonite presents strong colloidal properties and its volume increases several times when coming into contact with water, creating a gelatinous and viscous fluid (Stroes-Gascoyne, 2011).Bentonite clayused in this study is extracted from Caxuxi, Municipio de Santiago de Anaya, Valle del Mezquital, Hidalgo, Mexico.

Diatomaceous earth (D) can be used in food-grade (safe for human consumption) and non-food grade (used in industrial settings). Add D to potting soil to help it retain moisture and nutrients and allow oxygen to circulate freely, diverse applications becauseof its unique pore structure (Ivanov and Belyakov 2008). The diatomaceous earthused, Celite $209^{\circ}$ brand, is extracted from Zacoalco de Torres, Jalisco Mexico.

The additional material proposed to contribute to the correct elaboration of the pelletsand possibly increasing the survival percentage of the nematodes contained within was Sugarcane BagasseAsh (SCBA), which have been successfully used tostabilize soils in compressed blocks (Alavéz-Ramírez et al.,2012). SCBA is a waste and in Mexico is available in large quantities (Sheth, 2017).

The sugarcane bagasse ash was obtained from an open dump which belong to the sugar mill "Constancia", located at Tezonapa, Veracruz, Mexico. The SCBA is obtained by water sprinkling during the sugar production and deposited at open dumps. After the SCBA was collected it was sun dried and sieved through the sieve No. $4(4.75 \mathrm{~mm})$ ASTM, then homogenized and sieved again through the sieve No. $200(75 \mu \mathrm{m})$ during four minutes. 
The EPNs used were the species Steinernema glaseri from an original CEPA from the Entomology Laboratory at the University of California, Davis (USA). For the EPNs production, G. mellonella larvae (host) at the last instar were used as a host. The in vitro mass production and storage of the EPNs was in accordance with the recommendation of Kaya and Stock (1997).

The agesof test were chosen in accordance with the recommendations of Grewal (2002) who states that 21 and 30 days are critical stages for the survival ofEPN. The SRs of EPN encapsulate in pellets at roomtemperature has not been reported.

\subsection{Design of the Pellets}

In order to adequately manufacture the pellets (quasi-spherical shaped) and avoid their early disintegration, the decision was made to combine Bentonite clay plus Diatomaceous earth (B+D) and consider this combination as a control mixture.For manufacturing of the pelletsfour mixtures were prepared, the combinations and percentages of ingredients are show in Table 1.

Table 1. Mixture composition (wt. \%)

\begin{tabular}{|lcccc|}
\hline \multicolumn{1}{|c}{ Mixture } & $\begin{array}{c}\text { Designati } \\
\text { on }\end{array}$ & $\begin{array}{c}\text { Bentonite } \\
\text { (B) }\end{array}$ & $\begin{array}{c}\text { Diatomace } \\
\text { ous (D) }\end{array}$ & $\begin{array}{c}\text { Sugarcane Bagasse } \\
\text { Ash (SCBA) }\end{array}$ \\
\hline $\begin{array}{l}\text { Control (B+D) } \\
\text { Ternary 5 }\end{array}$ & C & 95 & 5 & - \\
(B+D+SCBA) & T5 & 90 & 5 & 5 \\
$\begin{array}{l}\text { Ternary 10 } \\
\text { (B+D+SCBA) }\end{array}$ & T10 & 85 & 5 & 10 \\
$\begin{array}{l}\text { Ternary 15 } \\
\text { (B+D+SCBA) }\end{array}$ & T15 & 80 & 5 & 15 \\
\hline
\end{tabular}

\subsection{Characterization of materials}

The chemical compositions of the materials were studied by the gravimetric and ICP methods using a Perking Elmer Optima $8300 \AA$ spectrometer. The mineral phases of the materials were identified using XR diffraction using an INEL, model EQUINOX 2000®. Finally, the morphologies of the materials were observed using a JEOL6300 JSM® scanning electron microscope.

\subsection{Production of pellets}

The procedure for the production of pellets was based on the principle discussed by Mendoza (2012) and Matadamas-Ortiz et al. (2014). The quantities of the materials for the preparation of the pelletswere determined by the mass of the ingredients according to each formulation proportion shown in Table 1.

The ingredients were dry mixed until a homogeneous powder was obtained, and then the powder was poured in an inverted frustum which had a lid at the bottom. Then, $200 \mu \mathrm{L}$ of deionized 
water were was added to the powder at the top of the frustum and the lid was removed. The water added to the powder agglutinated some particles and due to gravity small quasi-spherical shaped granules, called nuclei, were formed during their fall, according to the fluidized bed principle. Next, the nuclei were rolled on a rotating Archimedes spiral plate for 45 seconds in order to continue with the growing and consolidation of the pelletsFigure 1.
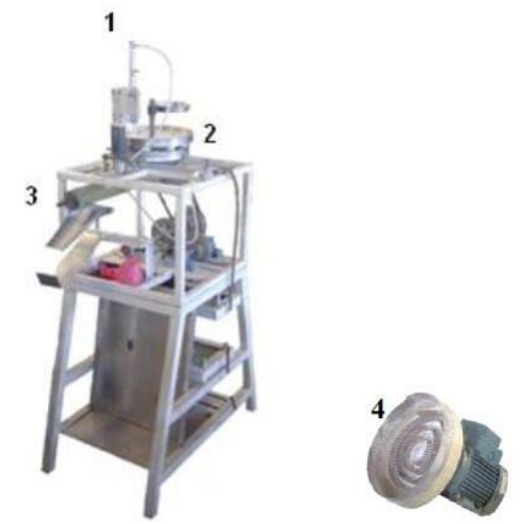

Figure 1. Nematode encapsulator (Taken from Mendoza, 2012)

1) Pneumatic aqueous solution dispenser containing nematodes, 2) Cones of accommodation of the granular material for the formation of the pellet, 3)Screw conveyor (pre compactor) and 4)

Compactor disc

\subsection{Capillary absorption of the pellets}

To evaluate the capillary absorption of the pellets, four pellets of each mixture were made without containing nematodes. Four cylindrical containers were used and linseed oil was added to each one until reaching a level of $2 \mathrm{~mm}$ above its base. Subsequently, the pellets were placed inside (Figure 2)and the weight gain of each of them was recorded in the following time intervals: $30,60,90,120,180,240,300,600,900,1200,1800,2100,2400,2700$ and 3600 seconds.

The oil content in each pellet was expressed as a fraction of oil (in percentage) with respect to the total dry weight of each pellet. Capillary absorption of the four pellets per mix was averaged to report capillary uptake for each mix.The tests were carried out at in two periods of time 21 and 30 days.

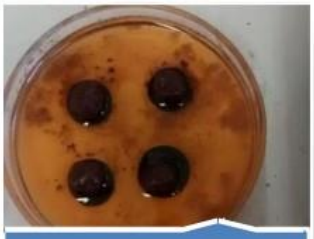

$95 \mathrm{~B}+5 \mathrm{D}$

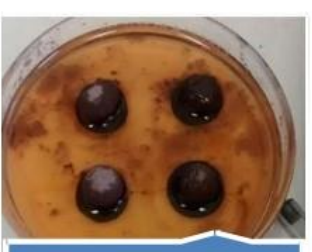

$90 \mathrm{~B}+5 \mathrm{D}+5 \mathrm{SCBA}$

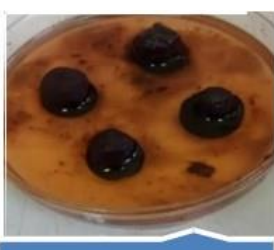

$85 \mathrm{~B}+5 \mathrm{D}+10 \mathrm{SCBA}$

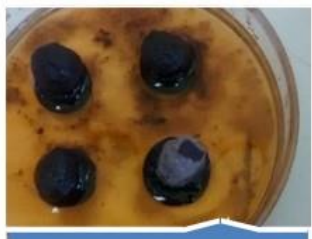

$80 \mathrm{~B}+5 \mathrm{D}+15 \mathrm{SCBA}$

Figure2. Test to evaluate the capillary absorption of the pellets 


\subsection{Reproduction of the EPNs}

The reproduction process of the EPNs implemented was that proposed by Kaya and Stock (1997). The G. mellonella larvae (host) were socked in $55^{\circ} \mathrm{C}$ deionized water for $15 \mathrm{~s}$, then socked in $15^{\circ} \mathrm{C}$ deionized water for $15 \mathrm{~s}$ to prevent the larvae reaching the pupal stage and to decrease their resistance to the EPN infestation. The larvae were laid on a Petri box where previously had been placed a filter paper $\left(5 \mathrm{~mm}\right.$ in diameter, $80 \mathrm{~g} / \mathrm{m}^{2}$ weight, $0.17 \mathrm{~mm}$ thick and pore size of 14 to $18 \mu \mathrm{m})$. Then $200 \pm 10 \mathrm{EPNs}$ per each larva were inoculated using $20 \mu \mathrm{L}$ of distilled water in order to produce moisture of $10 \mathrm{~g} / \mathrm{m}^{3}$ in the filter paper to ease the mobility of the EPNs and consequent infection of the larvaeFigure 3.

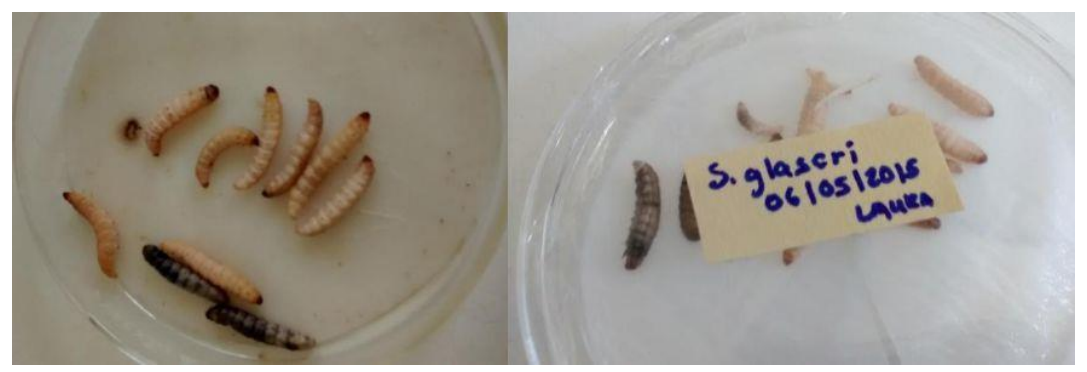

Figure3. Galleria mellonella larvae infected by EPNs

After five days following the infestation, the larvae were carefully transferred to $15 \mathrm{x} 8 \mathrm{~cm}$ white traps which contained $45 \mathrm{~mL}$ of distilled water. When the EPNs emerged from the larvae, they moved through the wet filter paper until reaching the distilled water where they were collected.

The water used at all times for the manipulation of the EPNs was $\mathrm{CO}_{2}$-free to prevent any kind of damage to the EPN during their conservation (Chen and Glazer, 2005). The EPNs were stored at 6- $8{ }^{\circ} \mathrm{C}$ for a week; after this storage time, the EPNs were available for encapsulation.

\subsection{Encapsulation of the EPN}

Prior to the encapsulation in the pellets, the EPNs were acclimated at $23{ }^{\circ} \mathrm{C} \pm 6{ }^{\circ} \mathrm{C}$ during $24 \mathrm{~h}$ (Chen and Glazer, 2005). Then, a solution containing $100 \pm 10$ EPNs per $200 \mu \mathrm{L}$ of water was prepared using the volumetric dissolution method in accordance with the recommendation of Petersen and Willis (1972). By the repeated water dropping technique of $10 \mu \mathrm{L}$, the amount of EPNs in the solution is determined; this procedure was repeated until the required concentration was achieved (Girón, 2008).

The solution was continuously stirred to keep a constant homogeneous concentration of $100 \pm 10$ EPNs, and in this way prevent the precipitation of the EPNs caused by the different densities.

Once the solution was prepared, the production of pellets +EPNs following the procedure previously described was carried out for the four formulation proportions established. The Figure 4 show appearance of pellets manufactured. 
Vol. 5, No. 06; 2020

ISSN: 2456-8643

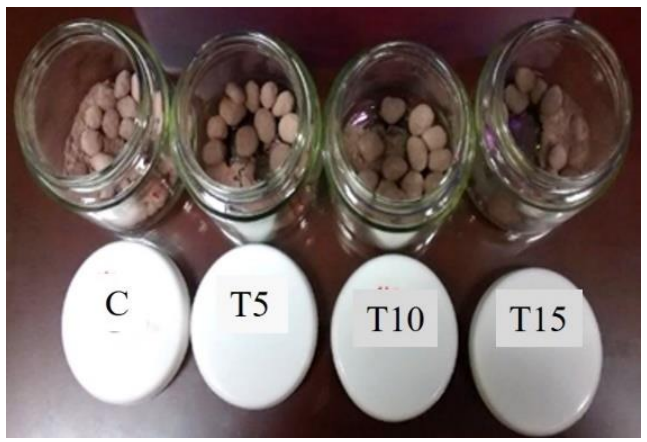

Figure 4. Appearance of the pellets(with nematodes inside) prepared with the fourmixtures

\subsection{Estimation of the EPN Survival Rates (SR)}

To estimate the EPNs SR, the pellets were placed in a9 $\mathrm{cm}$ Petri box and $10 \mathrm{ml}$ of distilled water were addedto provide the moisture required by the EPNs to recover mobility. The excess water served for the EPNs solution-making. A micropipette was used to take a $200 \mu \mathrm{L}$ sample from the EPNs solution and place it in a stereoscopic microscope to count the live and deadEPNs. The microscope used for the counting was anOlympus ${ }^{\circledR}$ with a 0.2 opening, a resolution of 600 pairsof lines per mm and a 30x zoom.

The identification of the live EPNs is straight forward because they move naturally or when stimulated with a needle. The EPNs were counted using the method proposed by Chen and Glazer (2005). Once the counting was concluded, the remaining sample was returned to the original solution and the counting process was repeated five times for each pellet. The EPNs counting was performed at 21 and 30 days, according to the experimental design.

\section{ANALYSIS OF THE RESULTS}

\subsection{Properties of the materials}

The results of the chemical analysis of the materials (Table 2) indicate that the main compounds present in powder materials are Silica and Alumina with low traces of $\mathrm{CaO}$ and $\mathrm{MgO}$ (Salem, 2015).The sum of major oxides is higher than 70\%; therefore, the materials have pozzolanic potential (ASTM C618- 12 ) and can react in an alkaline environment created by C (Malhotra, 1994).

Table 2. Chemical compositions of the materials (\%)

\begin{tabular}{|cccc|}
\hline Compound & B & D & SCBA \\
\hline $\mathrm{SiO}_{2}$ & 63.60 & 83.95 & 59.56 \\
$\mathrm{Al}_{2} \mathrm{O}_{3}$ & 14.25 & 3.11 & 13.62 \\
$\mathrm{Na}_{2} \mathrm{O}$ & 1.16 & $<0.03$ & $<0.03$ \\
$\mathrm{MgO}$ & 1.83 & $<0.005$ & 1.13 \\
$\mathrm{~K}_{2} \mathrm{O}$ & 3.05 & 0.12 & 3.25 \\
$\mathrm{CaO}$ & 2.45 & 0.34 & 2.22 \\
$\mathrm{Fe}_{2} \mathrm{O}_{3}$ & 3.68 & 1.62 & 5.52 \\
$\mathrm{FeO}$ & $<0.01$ & $<0.01$ & 0.7
\end{tabular}


Vol. 5, No. 06; 2020

ISSN: 2456-8643

\begin{tabular}{|cccc|}
$\mathrm{P}_{2} \mathrm{O}_{5}$ & 0.11 & $<0.06$ & 0.96 \\
$\mathrm{MnO}$ & 0.04 & 0.01 & 0.33 \\
$\mathrm{LOI}$ & 9.28 & 11.13 & 10.78 \\
\hline $\mathbf{2} \mathbf{S i O}_{2}+\mathbf{A l}_{2} \mathbf{O}_{3}+$ & $\mathbf{8 5 . 6 8}$ & $\mathbf{8 8 . 6 8}$ & $\mathbf{7 8 . 7}$ \\
$\mathbf{F e}_{2} \mathbf{O}_{3}$ & & & \\
\hline
\end{tabular}

Figure 5 shows that $\mathrm{B}$ and $\mathrm{D}$ exhibit an amorphous halo between $15-35^{\circ} 2 \theta$ angle (Bahurudenn, 2015) which is an indication of the reactivity of some phases of the materials, and when they are combined with alkali-rich materials, such as Calcium Hydroxide, can be used to produce stronger cementitious materials (Bahurudeen, 2015).Figure 4 also confirm that the B has Montmorillonite, Quarz and Cristoballite (He, 2015; Salem, 2015) while the D has Orthoclase and Quartz (Liu, 2014), the SCBA has Quartz, Cristoballite, Calcite and Magnetite (Martirena, 1998), The combination of the phases of these materials can help to make the pellets stable.

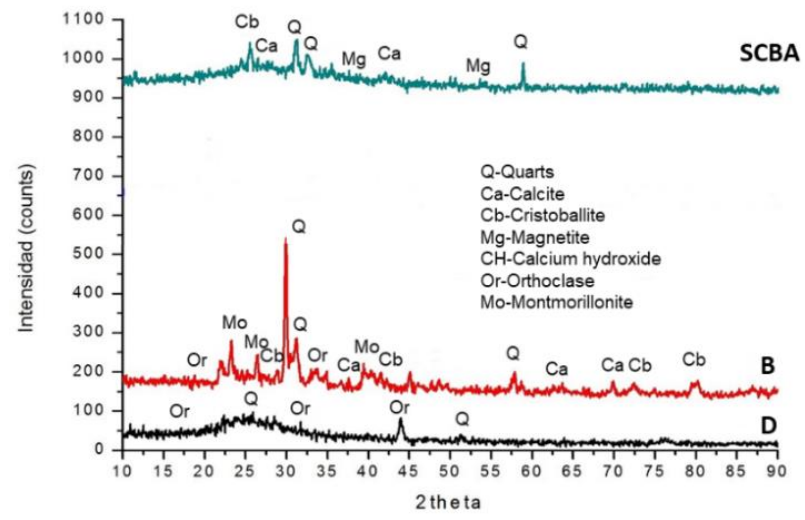

Figure 5. Patterns of the mineral phases of materials

In Figure 6 the different shapes and sizes of thematerials are observed. For example, the bentonite (B) particles are laminar in shape which is characteristic of a smectite mineral with discontinues cavities between plates in their basic structural units, Figure 6a. The D particlesshow coscinodisophyceae (radial symmetry) andfragilariophyceae (bilateral symmetry, or sternumpseudolateral) shapes with open pores which allowaccommodating solids, Figure6b coinciding with what was reported by Sun et al., 2013. The SCBA is a heterogeneous material with particles of different sizes and shapes, Figure6c, Driemeier et al., (2011) published similar micrographs. The particles can be classified as prismatic, spherical and fibrous. According to Batra et al., (2008) that prismatic particles consist mainly of $\mathrm{Si}$ and $\mathrm{O}$, while spherical particles consist of $\mathrm{Si}, \mathrm{O}, \mathrm{Na}, \mathrm{K}, \mathrm{Al}, \mathrm{Mg}$ and $\mathrm{Ca}$; while Umamaheswaran and Batra, (2008) said that fibrous particles consist mainly of carbon. 


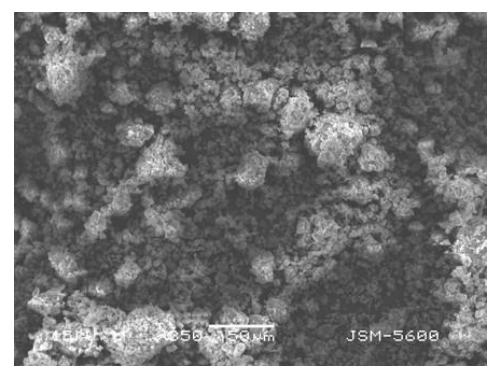

$\mathrm{a}$

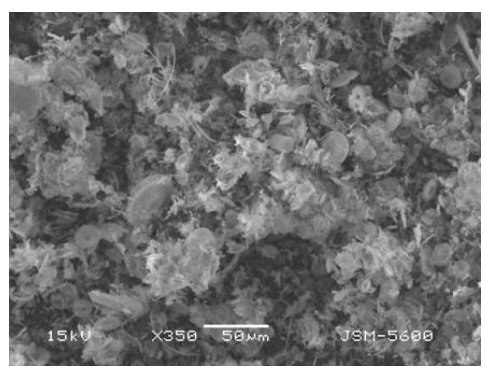

b

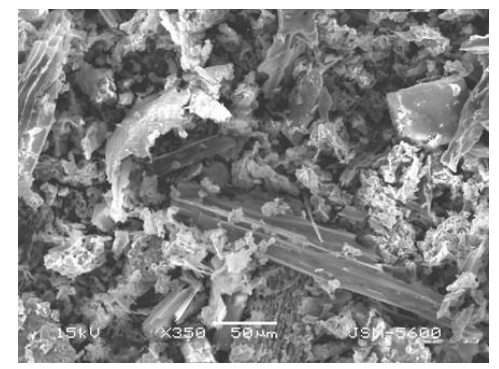

c

Figure 6. Morphology of the materials

a) Bentonite, b) Diatomaceous earth, c) Sugarcane Bagasse Ash

\subsection{Capillary absorption}

Figure 7 shows the results of the capillary absorption tests of pellets with a maturation age of 21 days.

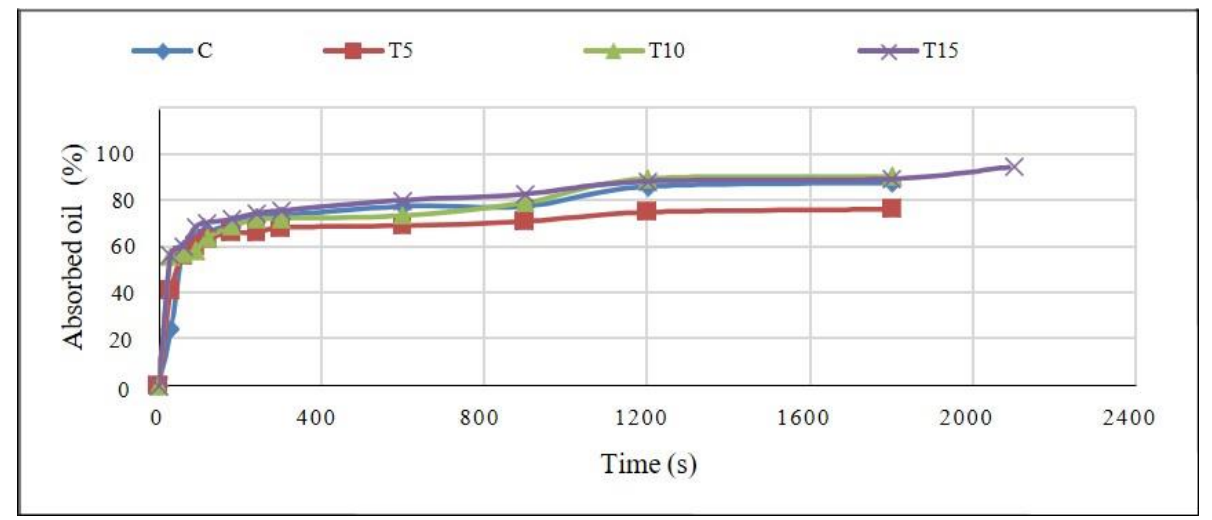

Figure 7.-Capillary absorption of pellets at 21 days of maturation

It is observed that the pellets made with the four mixtures followed the same trend in their absorption capacity. From 0 to 240 seconds was the period of time in which there was a higher percentage of absorption (about $70 \%$ of the total) and from 240 seconds, the percentage of absorption was lower. The pellets made with the T15 mixture had the longest time to saturate (2300 seconds), this can be attributed to the fact that in this mixture there is a higher concentration of $\mathrm{Ca}^{2+}$ ions, thus reducing its absorption speed (Kawatra, et al 2003).

Figure 8 shows the results of the capillary absorption tests of pellets with a maturation age of 30 days. 


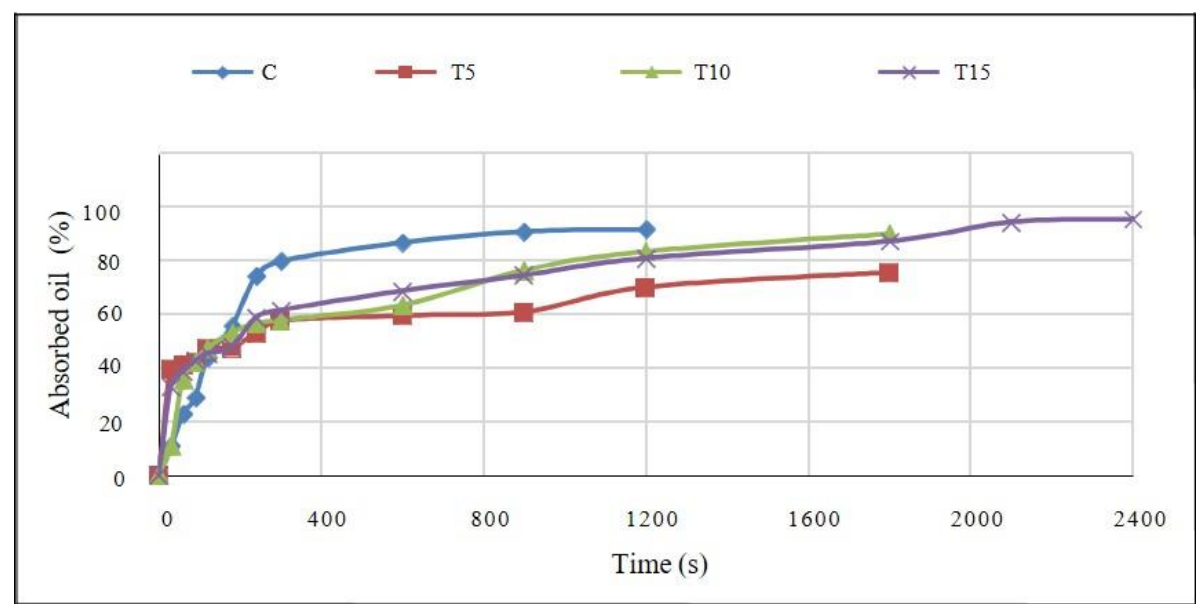

Figure 8.-Capillary absorption of pellets at 30 days of maturation

For the maturation age of 30 days, the pellets show a similar absorption tendency only during the first 240 seconds (they absorb approximately $40 \%$ of the total), after this time the absorption is slightly different for all the pellets. The pellets made with mixture $\mathrm{C}$ had the highest absorption capacity and saturated in the minor time (1200 seconds), this effect is due to the irregular geometry of the $\mathrm{B}$ and $\mathrm{D}$ particles that prevent adequate packing and leave a greater number of open pores (Sergiy et al., 2005).

The pellets made with the T5 mixture presented lower absorption capacity and were saturated at a time of 1800 seconds. The pellets made with the T10 and T15 mixes had a similar absorption capacity, however, the pellets made with the T15 mix had the longest saturation time of 2400 seconds. This behavior is due to the SCBA having a high LOI percentage $(>10 \%)$, the high LOI content can be considered as an indication of high levels of unburned carbon. Chandara et al, (2010) found that high levels of unburnedcarbon particles result in an increase in the requirementfor water and other liquids because the liquids are absorbedby carbon particles.

\subsection{Estimation of the EPNs Survival Rate (SRs)}

In Figure 9 the results of the SRs of EPNs estimated at 21 days are presented and analyzed next. The nematodes encapsulated inside the pellets manufactured with the T10 mixture $(85 \mathrm{~B}+5 \mathrm{D}+10 \mathrm{SCBA}$ formulation) had the highest survival rate $(62 \%)$ and the nematodes encapsulated inside the pellets made with the control mix $(C)(85 \mathrm{~B}+5 \mathrm{D}$ formulation $)$ had the lowest survival rate (11\%). Finally, the pellets manufactured with T5 an T15 mixture had similar SRs of EPN encapsulated (33\% and $35 \%$ respectively). 


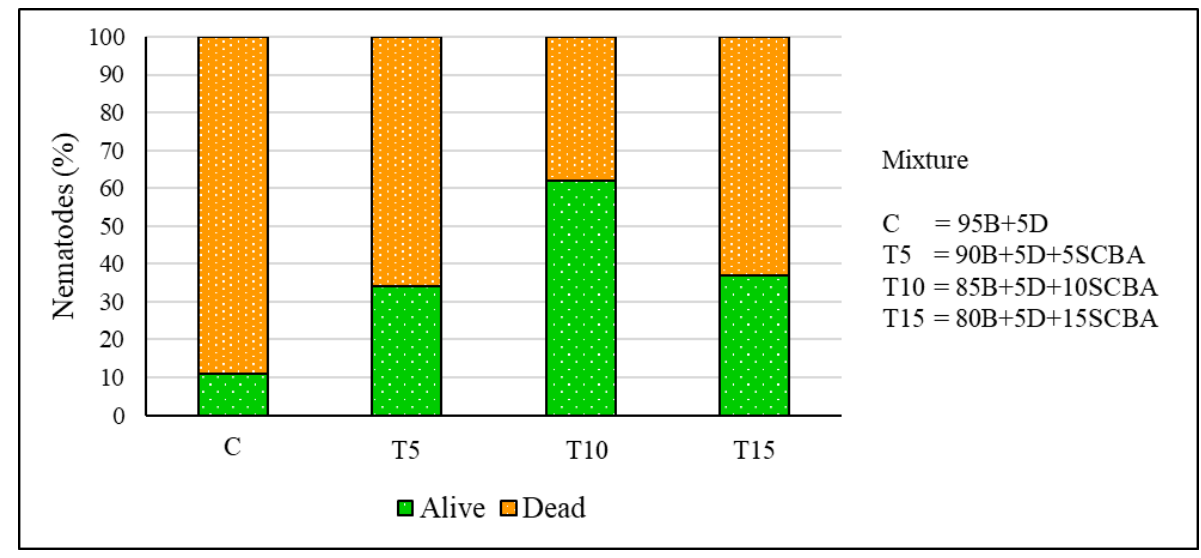

Figure 9. Survival rates nematodes at 21 days

In Figure 10 the results of the SRs of EPN estimated at 30 days are presented. At 30 days the SRs of the EPNs encapsulated in the pellets of all the mixtures were slightly lower than those obtained at 21 days.At this age, the pellets manufactured with the T10 mixture had again the highest SR (48\%) and the pellets manufactured whit C mixture had the lowest SR (9\%). The SRs for the T5 y T10 mixtures was practically the same.

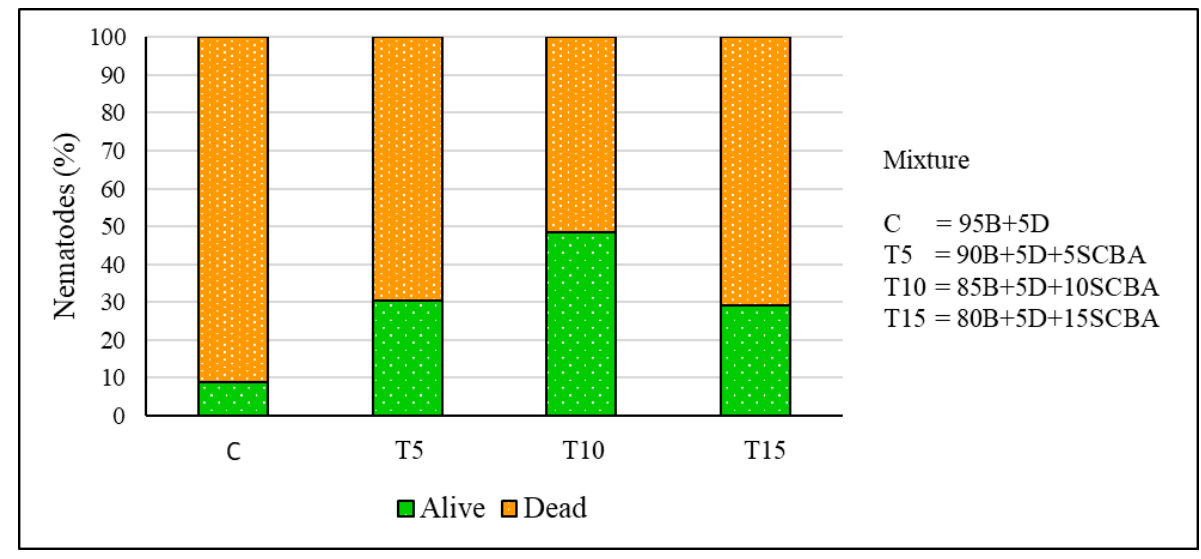

Figure 10. Survival rates nematodes at 30 days

Results confirm that the amount and type of granular material added into the different formulations had significant beneficial effects on the SR of the EPNs (Steneirnemaglaseri).

The combination of powder materials of different chemical and physical characteristics contributes to improve the adhesion and bond between the solid particles' surfaces. When powder materials are used the surface area, density, porosity and shape of the particles play a significant role in the agglomeration process because such properties define the adherence and cohesion of the particles (Mort, 2005).

The interaction between bentonite and diatomite was beneficial as they formed a compact structure (He, et al. 2015). Bentonite provided a source of colloidal material that increased van der Waals forces and formed a solid, hardened gel bridge that strengthened the contact points 
Vol. 5, No. 06; 2020

ISSN: $2456-8643$

between its particles (Kawatra and Ripke, 2003). On the other hand, with the addition of diatomite, hydrogen bonds were increased, improving the adherence between particles in the wet state (Imbert and Villar, 2006). With the addition of cane bagasse ash, the flow and transport properties of liquid inside the pellet were improved.

In addition, the use of $10 \%$ sugarcane bagasse ash in the base materials $(B+D)$ improved the survival percentage of NEPs, probably due to its hydrophilic capacity since it conserves moisture inside the pellet for a longer time.

Greater amounts (more than 10\%) of ash produced a loss of cohesion between the particles of the powdered materials and therefore the conditions for the survival of the nematodes were modified (PimraksaandChindaprasirt, 2009), the above generated difficulties in the reactivation of the physiological functions of the EPNs after having been exposed to anhydrobiosis (Grewal, 1999) and therefore affected the emergence of EPNs.

\section{CONCLUSIONS}

The combination of powder materials of different chemical and physical characteristics contributed to improve the adhesion and bond between the solid particles' surfaces.

The addition of SCBA to the mixture of powdered $(B+D)$ materials for the manufacture of pellets, improved the absorption and water retention capacity in them, which was beneficial in increasing the survival rate of EPNs.

The combination of $90 \% \mathrm{~B}+5 \% \mathrm{C}+10 \% \mathrm{SCBA}$ for the manufacture of pellets increases the EPN survival rate $51 \%$ with respect to the control mixture at 21 days. Using amounts of SCBA greater than $10 \%$ causes greater water absorption, expansion and disintegration of the pellets; therefore, the death of more nematodes.

\section{ACKNOWLEDGEMENTS}

The authors are grateful for the financial support of the Consejo Nacional de Ciencia $y$ Tecnología of Mexico (CONACyT), the InstitutoPolitécnico Nacional of Mexico (IPN), COFAA-IPN, PIFICOFAA-IPN Program, CIIDIR-IPN-Oaxaca. The authors also thank the Universidad Autónoma del Estado de Hidalgo (UAEH) and the Faculty of Materials Engineering of the UAEH (FIM-UAEH), as most of the testing was carried out in this institution.

\section{REFERENCES}

Alavéz-Ramírez, R., P. Montes-García, J. Martínez-Reyes, D. C. Altamirano-Juárez, and Y. Gochi-Ponce. 2012. The use of sugarcane bagasse ash and lime to improve the durability and mechanical properties of compacted soil blocks. Construction and Building Materials, 34: 296305. https://doi.org/10.1016/j.conbuildmat.2012.02.072

Bahurudeen, A., D. Kanraj, V. G. Dev and M. Santhanam. 2015. Performance evaluation of sugarcane bagasse ash blended cement in concrete. Cement and Concrete Composites, 59: 77-88. https://doi.org/10.1016/j.cemconcomp.2015.03.004 
Vol. 5, No. 06; 2020

ISSN: $2456-8643$

Batra, V.S., S. Urbonaite, and G. Svensson. 2008. Characterization of unburnt carbon in fly ash bagasse. Fuel, 87 (13-14): 2972-2976. https://doi.org/10.1016/j.fuel.2008.04.010

Chandara C, Sakai E, Azizli KAM, Ahmad ZA, Hashim SFS. The effect ofunburned carbon in palm oil fuel ash on fluidity of cement pastes containingsuperplasticizer. Constr Build Mater 2010;24:1590-3.

Chen, S., and I. Glazer. 2005. A novel method for long-term storage of the entomopathogenic nematode Steinernemafeltiae at room temperature. Biological Control, 32 (1): 104-110. https://doi.org/10.1016/j.biocontrol.2004.08.006

Driemeier, C.; Oliveira, M.M.; Mendes, F.M.; Gómez, E. O: (2011) Characterization of sugarcane bagasse powders. Powder Technology. Vol 214 (12): 111-116.

Grewal, P.S. 2002. Formulation and application technology. In R. Gaugler, (Ed.), Entomopathogenic Nematology, Wallingford, Oxford shire: CABI. pp. 288. https://DOI $10.1079 / 9780851995670.0000$

Girón, P. S., 2008. Evaluation of two formulations of entomopathogenic nematodes to control white grub (Phyllophagavetula) in maize. Unpublished dissertation in partial fulfillment of the requirements for the degree of Master in sciences. Instituto Politécnico Nacional CIIDIROaxaca, Mexico.

He, Y.; Wu, Z.; Tu, L.; Han, Y.; Zhang, G. Li, Ch. (2015). In capsulation andcharacterization of slow-release microbial fertilizer from the composites of bentoniteand alginate. Applied Clay Science. (109-110):68-75.

Hiltpold, I., B.E. Hibbard, B.W. French, and T.C.J. Turlings. 2012. Capsules containing entomopathogenic nematodes as a Trojan horse approach to control the western corn rootworm. Plant and Soil, 358 (1-2): 11-25. DOI 10.1007/s11104-012-1253-0

Imbert Christophe, Villar M. Victoria. Hydro-mechanical response of a bentonite pellets/powder mixture upon infiltration. Applied Clay Science 32 (2006) 197-209

Ivanov, S.É., Belyakov, A.V. Diatomite and its applications. Glass Ceram 65, 48-51 (2008).https://www.researchgate.net/publication/226838666_Diatomite_and_its_applications

Kaya, H.K., and S.P. Stock. 1997. Techniques in insect nematology. In L.A. Lacey (Ed.), Manual of Techniques in Insect Pathology. San Diego, CA: Academic Press, Klein. pp. 281-324. https://doi.org/10.1016/B978-012432555-5/50016-6

Kuwatra and Ripke, 2003 S. KomarKawatra, S. Jayson Ripke. Laboratory studies for improving green ball strength in bentonite-bonded magnetite concentrate pellets. Int. J. Miner. Process. 72 (2003) $429-441$.

Liu, Y., D. Scharf, T. Graule, and F. J. Clemens. 2014. Granulation processing parameters on the mechanical properties of diatomite-based porous granulates. Powder Technology, 263: 159-167. https://doi.org/10.1016/j.powtec.2014.04.094 
Malhotra, V.M.; Ramezanianpour, A.A. (1994).Fly Ash in Concrete. (p.19-31). CanadáCentre for Mineral and Energy Technology. Second edition

Martirena, H.J.F., Middendorf, B., Gehrke, M., Budelmann H. (1998). Use of wastes of thesugar industry as pozzolana in lime-pozzolana binders: study of the reaction. Cement and Concrete Research, 28:1. pp. 1525-1536.

Matadamas-Ortiz, P. T., J. Ruiz-Vega, J.A. Vázquez-Feijoo, H. Cruz-Martínez, and C.I. CórtesMartínez. 2014. Mechanical production of pellets for the application of entomopathogenic nematodes: factors that determine survival time of Steinernema glaseri. Biocontrol Science Technology, 24(2): 145-157. https://doi.org/10.1080/09583157.2013.852161

Mendoza, P. M., 2012. Effect of pellet hardness on the mortality of mechanically encapsulated entomopathogenic nematode Steinernemaglaseri. Unpublished dissertation in partial fulfillment of the requirements for the degree of Master in sciences. InstitutoPolitécnico Nacional CIIDIROaxaca, Mexico.

Mort P. (2005) Scale-up of binder agglomeration processes. Powder Technology. 150, 86103

Petersen, J.J., and O. R. Willis. 1972. Procedures for the mass rearing of a mermithid parasite of mosquitoes. Mosquitoes News, 32(2): 226-230. https://www.biodiversitylibrary.org/content/part/JAMCA/MN_V32_N2_P226-230.pdf

Pimraksa, K. and Chindaprasirt, P. (2009). Lightweight bricks made of diatomaceous earth, lime and gypsum. Ceramics International. Vol. 35:1. pp. 471-478.

Salem, S.; Salem, A.; Agha-Babaei, A. (2015) Preparation and characterization of nanoporous bentonite for generation of semi-treated waste engine oil applied aspects forenhanced recovery. Chemical Engineering Journal. Vol 260: 368-376.

Sheth K. (2017, April 25). Top Sugarcane Producing Countries. Retrieved fromhttps://www.worldatlas.com/articles/top-sugarcane-producing-countries.html.

Silver, S.C., D.B. Dunlop and D.I. Grove, 1995. WIPO Patent No. WO 95/0577. Geneva: World Intellectual Property Oerganization. https://patents.google.com/patent/US5622658A/en

SergiyAntonyuk, Jürgen Tomas, Stefan Heinrich, LotharMörl. Breakage behaviour of spherical granulates by compression. Chemical Engineering Science 60 (2005) 4031 - 4044.

Stojiljković S.T., Stojiljković M.S. (2017) Application of Bentonite Clay for Human Use. In: Lee B., Gadow R., Mitic V. (eds) Proceedings of the IV Advanced Ceramics and Applications Conference. Atlantis Press, Paris. https://doi.org/10.2991/978-94-6239-213-7_24

Stroes-Gascoyne, S.; Hamon C.J.; Maak, P. (2011) Limits to the use of highly compactedbentonite as a deterrent for microbiologically influenced corrosion in a nuclear fuel wasterepository. Physics and chemistry of the earth. (36) pp. 1630-1638. 
International Journal of Agriculture, Environment and Bioresearch

Vol. 5, No. 06; 2020

ISSN: $2456-8643$

Sun, Z.; Yang, X.; Zhang, G.; Zheng, S.; Frost, R.L. (2013). A novel method for purificationof low grade diatomite powders in centrifugal fields. International Journal of MineralProcessing.125: 18-26

Umamaheswaran, K., and V.S. Batra. 2008. Physico-chemical characterization of Indian biomass ashes. Fuel, 87(6): 628-638. https://doi.org/10.1016/j.fuel.2007.05.045 